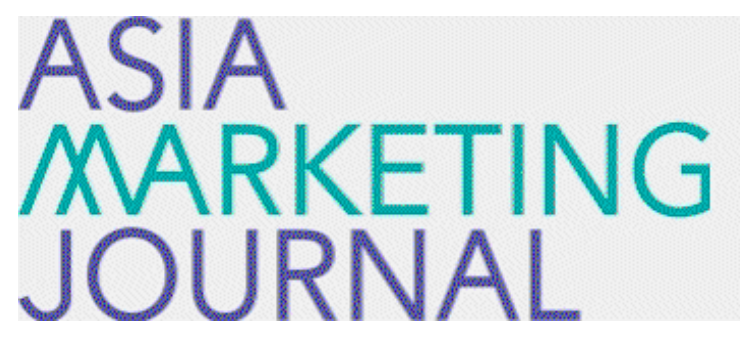

ASIA MARKETING JOURNAL

Volume 1 | Issue 1

Article 1

$12-1-1998$

\title{
Corporate Strategies for the 21st Century With Special Emphasis on Global Marketing Strategies
}

Dong Ki Kim

Follow this and additional works at: https://amj.kma.re.kr/journal

Part of the Marketing Commons

\section{Recommended Citation}

Kim, Dong Ki (1998) "Corporate Strategies for the 21st Century With Special Emphasis on Global Marketing Strategies," Asia Marketing Journal: Vol. 1 : Iss. 1 , Article 1.

Available at: https://doi.org/10.53728/2765-6500.1000

This Article is brought to you for free and open access by Asia Marketing Journal. It has been accepted for inclusion in Asia Marketing Journal by an authorized editor of Asia Marketing Journal. 


\title{
Corporate Strategies for the $21^{\text {st }}$ Century
}

\section{With Special Emphasis on Global Marketing Strategies}

Dong Ki Kim, Ph. D

\author{
Professor \\ College of Business Administration, Korea University \\ Member \\ The National Academy of Sciences, \\ The Republic of Korea
}


Nowdays, the world economic system is dominated by two major organizing forces : globalization and regionalization. Globalization forces are stirring significant change throughout the world and creating a new world economic order as the world approaches the 21 st century.

Development in transportation and telecommunications along with easy access to information has transformed the world into a global community. This transformation has been accelerated by a series of dramatic political changes, the implementation of more open policies toward trade and investment, and a substantial expansion in crossborder interactions involving the movements of capital, technology, culture as well as personnel.

Consequently, national economies are becoming increasingly interdependent and in particular, firms are increasingly conducting business on a global scale. As such, the concept of a national enterprise is rapidly fading away, and we are witnessing the emergence of truly transnational firms in the international marketplace. Due to these factors, national borders are now becoming rather insignificant. As Kenichi Ohmae suggests, we may be on the verge of truly becoming a " borderless world" or "borderless global village".

In recent years, however, we have seen the world economy evolve into a bipolar structure: globalization and regionalization. Particularly, cooperative regional groupings are starting to predominate the world economic scene as individual countries are beginning to seek ways of confronting these worldwide changes.

This trend towards regionalization is the most clearly manifested in the growth of intra-regional trade blocs within Europe, North America and the Southeast Asia respectively. The EC has embarked on a new voyage as the European Union(EU) with the effectuation of the Maastricht Treaty. The EU will not only utilize a common currency but also will pursue common diplomatic and security policies in the future. The United States, Canada, and Mexico have successfully established the North American Free Trade Agreement(NAFTA). It is quite possible that NAFTA will eventually be expanded to include some Latin American countries as well. The ASEAN countries too have launched the ASEAN Free Trade Area(AFTA), and have agreed to enlarge their membership recently.

Although a worldwide trend towards regionalization is seen in every region these days, each region will not only compete but also cooperate with each other for mutual 
interest within the context of globalization. For this reason, interest in economic and financial cooperation among nations on a global scale is rapidly increasing recently, especially considering the complementary relationship of nations through interdependency in the trade and investment.

The most striking trend in business today is the growing globalization of markets worldwide. This is true for everything from airlines to automobiles, baking to burgers, clothing to computers, detergents to diapers, electronics to elevators, ... soft drinks to software, toothpastes to tacos.

Although multinationals such as Unilever and Nestle have long been prominent features of the international business scene, the current trend toward globalization and the emergence of global markets essentially occurred from the '60s. The '60s observed greater operation of U.S. companies abroad. Then in the '70s Japanese companies became major contenders in markets ranging from consumer electronics to heavy construction equipment. During the '80s new world multinationals whose home bases were in industrializing countries in the Far East or in developing economies in Latin America have emerged. As the result of increased competition, the '90s witnessed global restructuring, in which many firms moved toward streamlining international operations and improving global efficiencies in order to survive.

What would we observe during the next decade? I believe that changes undertaken in the '90s will continue. More specifically, a global firm will have to find a balance between two conflicting demands: on the one hand, it needs to achieve a low cost position by removing duplication of activities in its value chain and globally standardizing its products. On the other hand, it needs to differentiate its offers by locating activities closer to the customers and adapting products to the customer' s needs in each country. I will elaborate on this issue later.

Today, I would like to talk about important elements of business strategy that every successful global firm in the 21 st century must be familiar with. Global strategy consists of the following five elements: assessing transferability of core competence, configuring value chain worldwide, deciding on the markets to enter, selecting modes of entry, and finally coordinating activities.

The first element is to assess transferability of core competence. ${ }^{1}$ Before developing global strategy, the firm should define its core competence and assess if it can be transferred to other countries. Core competence refers to the specific skills and 
assets that determine the firm's distinctive competitive advantage relative to other firms. In general, core competence is difficult to imitate. For example, Caterpillar has core competence in product quality, worldwide dealer network and fast after-sales service, and brand name. In contrast, Komatsu's core competence lies in low cost and high quality which were achieved through a series of total quality programs.

A firm's core competence may not provide a competitive advantage in foreign markets due to differences in customer requirements or competitive offerings. For example, technically complex, labor-saving agricultural machinery may not find a market in developing countries, where labor costs are low and agricultural laborers do not have the necessary skills to operate and maintain it effectively.

A local competitor with a similar core competence may already have established a strong position in the local market, which may be difficult to challenge. For example, McDonalds in Bombay, India faces competition from local businesses that deliver individual home-cooked meals to offices by bicycle, as well as local restaurants selling veggie burgers.

In general, skills in upstream areas such as product $R \& D$, process and production technologies are often more readily leverageable than skills in downstream activities such as marketing, distribution, and service. For example, $P \& G$ leverages the expertise of its Japanese R\&D unit in surfactant technology to develop detergent products for other parts of the world. Similarly, Japanese automobile manufacturers such as Toyota and Honda have been able to transfer their production management skills to other countries such as the United States and the U.K.

Marketing and distribution skills are typically less readily transferable. For example, Radio Shack was unsuccessful in attempting to transfer its concept of stores selling private label merchandise to Europe because European customers relied heavily on salesperson's advice in making their decisions and preferred to purchase national brands.

If the firm's core competence cannot be directly transferable, some adaptation may be required. For example, in Japan, foreign firms have to learn how to establish relations with distributors at both the wholesale and retail level, and furthermore, how to gain their trust and confidence.

While it is important to assess and utilize its core competence in foreign markets, it is also important to acquire core competence the firm lacks through globalization. For 
example, in 1997 alone Daewoo Motors was able to introduce 3 entirely new passenger car models in Korea. It was a remarkable achievement for Daewoo since for a long time its $R \& D$ capabilities were regarded as falling behind those of its rival Hyundai. The secret behind the Daewoo's achievement lies in its overseas research centers located in Warding, England and Munich, Germany which Daewoo acquired a few years ago as a part of its globalization program.

Having identified transferable core competence it has, the firm needs to consider the next element of global strategy, namely where to configure or locate its value chain worldwide. The importance of strategic thinking in activity location cannot be overemphasized. Since locations cannot be changed easily, a firm will have to bear the consequences of sub-optimal locations for a long time. ${ }^{2}$

The classic export-based approach has been to locate as much of the value chain as possible back home, while locating overseas only downstream activities, such as selling, distribution, and service, that have to be performed close to the end-customer. However, one should realize every functional or value-adding activity, from research to manufacturing to customer service, is a candidate for globalization. The multinational approach has gone to the other extreme and reproduced activities in many countries, particularly the production function by setting up factories and other manufacturing assets. It has resulted in too much duplication of activities, leading to inefficiencies. For example, Unilever once operated 13 factories for soap production in Europe alone.

The global strategy for activity location involves a third approach, locating each individual activity in one or a few countries that are most appropriate for that activity. So a business pursuing a global activity strategy might locate research in the United Kingdom, development in Germany, raw material processing in Mexico, subassembly in the United States, final assembly in Ireland, and so on. It is necessary to note that the global strategy allows for some duplication in activity location. Unilever had reduced the 13 soap factories in Europe down to 3, not 1. And Nike has reduced the number of warehouses in Europe from 35 to 5 . Such duplication provides security against supply disruptions and provides some flexibility in the system. Consider the example of Texas Instrument. ${ }^{3}$

Texas Instrument (TI) engineers scattered across the globe can work on the same project 24 hours a day, thanks to the company's advanced computer network. When a U.S. financial exchange asked TI to come up with a quote to make a hand-held 
electronic bidding device for traders, the company's design department began working on the problem in Dallas, then at quitting time electronically sent what they had done to designers in Tokyo, who when their work day ended passed it on to designers in Nice, France. By the next day in Dallas, TI not only had a pretty accurate quote but could also show the customer a computer-generated photo of what the product would look like.

The next element in global strategy is deciding on the markets to enter. Traditionally, multinational companies selected country-markets on the basis of standalone attractiveness. However, global strategy requires firms to consider how participation in a particular country-market will contribute to the global competitive position of the business. ${ }^{4}$

The internationalization history of Heineken, the Dutch brewer, provides a classic example of choices made on the basis of stand-alone attractiveness. Heineken's first international markets were Egypt, Sri Lanka(Ceylon), Singapore, Indonesia, and the West Indies. What did these five countries have in common? They were either Dutch colonies or on shipping routes to each of them. These factors made those markets very attractive to Heineken, even though each country had little effect on Heineken's global position. Of course, Heineken now recognizes the strategic importance of key markets like North America. The company has a major target of building up its business in the United States and Canada, which accounted for less than $10 \%$ of sales in the early '90s. Similar stories can be found among Korean multinationals.

Recently, a major newspaper in Korea reported that Korean automobile and consumer electronics firms held the largest market shares in several countries around the world, beating rival Japanese firms. Unfortunately, however, the list of countries reported in the article was dominated by strategically unimportant countries such as Puerto Rico, Syria, Iran, Lebanon, Nigeria, Algeria, Jordan, and Peru. Who cares if Kia Motors became No. 1 player in Syrian commercial vehicles market by selling just 2100 cars?

Perhaps the most important difference between market selection for the sake of internationalization and globalization is the role of globally strategic countries. Such countries are important beyond their stand-alone attractiveness. There are several ways in which a country can be globally strategic as a market:

* Large source of revenues or profits 
The larger the market, the more it can contribute to the firm's global scale economies. Success in a large market can, therefore, drive down worldwide costs. Success in a large market can also provide funds to subsidize the business in other small markets.

* Home market of global customers

Global firms need a strong presence in the home market of global customers. Relationships can be maintained best in the customer's home market. In addition, major customers are the key source of ideas for innovation. So it is important to have a research and development presence in these customers' home markets. For example, as many as 16 automobile makers have their design centers in California's "Design Valley."

* Home market of global competitors

For many global competitors their home market represents a major source of revenues or profits. A business needs a strong presence in these hostile home markets both in order to limit funds to flow to its competitors and to act as a hostage for good behavior. In this respect, IBM's early and highly successful commitment to Japan has probably helped to reduce the global threat it faces from Fujitsu. Stunting the domestic growth of foreign competitors is, of course, cheaper than fighting them after they have grown to global scale.

\section{* Lead countries}

Lead countries refer to those few countries in which innovations in products or processes tend to occur most frequently. For example, Japan for consumer electronics, United States for computer software, Germany for industrial control equipment. It becomes critical for global firms to participate in these lead countries in order to be exposed to the sources of innovation.

While it is important to have a strong presence in globally strategic markets, the business should not have most of its revenues concentrated in just a few countries, and its market share in each country should not be too vary from its global market share. The reason is that a business with imbalanced market participation will find it difficult 
to make effective integrated competitive moves. Because of its weakness in many markets, such a business will have fewer opportunities for making preemptive moves against competitors. A competitor with a large share but limited presence can be less of a threat than a competitor with a smaller share but broader market presence.

Having decided on the markets to enter, the next step is to select the mode of entry. Generally, the choices are indirect exporting, direct exporting, licensing, joint ventures, and direct investment. Each succeeding entry mode involves more commitment, risk, control, and profit potential. Since advantages or disadvantages of each of these entry modes are very well known, I would not reiterate them here. In determining the mode of entry, the firm should consider four sets of factors. ${ }^{5}$ Two of these, core competence and international experience of the firm, are internal factors. The other two, industry and country characteristics, are external factors. For example, Daewoo Group relies heavily on acquisitions in entering foreign country-markets. About $20 \%$ of Daewoo's 311 foreign operations were established through acquisitions. Daewoo has been effectively utilizing one of its core competences, acquiring bankrupt firms at a very favorable price and then turning them around in a short period of time. By doing so, Daewoo was able to enter rapidly several key markets including Eastern Europe. Recent $\$ 5$ billion capital infusion from G.M. to Daewoo Motors was made possible partly because G.M. wanted to take advantage of Daewoo's strong presence in such markets.

Final element of global strategy is coordinating activities worldwide. That is, global firms should integrate activities such as $\mathrm{R} \& \mathrm{D}$, manufacturing, or marketing conducted around the world. Basically, the issue boils down to how much the firm should integrate its various activities constituting the value chain. Since I am putting a particular emphasis on global marketing in this paper, let me first elaborate on marketing. In marketing, the coordination problem has been known as "standardization vs. adaptation" issue.

The marketing concept holds that customers' needs vary and that marketing programs will be more effective when tailored to each target market. Since this concept applies within a country, it may also apply in foreign markets. Yet many multinationals are bothered by an excessive amount of adaptation. Take an example of Gillette. $^{6}$

Gillette sells over 800 products in more than 200 countries. It has fallen into a 
situation where different brand names are used for the same product in different countries, and where the same brand is formulated differently in different countries. Gillette's Silkience shampoo is called Soyance in France, Sientel in Italy, and Silience in Germany; its formula is the same in some cases but varies in others. Its advertising messages and copies are also varied because each Gillette country manager proposes several changes that he or she thinks will increase sales.

Gillette would like to impose more standardization, globally or at least regionally in order to save costs and to build up global brand power. Professor Theodore Levitt of Harvard Business School supplied the intellectual rationale for global standardization. He wrote:

The world is becoming a common marketplace in which people - no matter where they live - desire the same products and lifestyles. Global companies must forget the idiosyncratic differences between countries and cultures and instead concentrate on satisfying universal drives. ${ }^{7}$

Levitt believes that new communication and transportation technologies have created a more homogeneous world market. People around the world want the same basic things - things that make life easier and increase their discretionary time and buying power. This convergence of needs and wants has created global markets for standardized products.

According to Levitt, traditional multinational corporations focus on differences between specific markets. They cater to superficial preference differences and produce a proliferation of highly adapted products. Adaptation tends to result in lower efficiency and higher prices to consumers. For example, Black and Decker operated 25 plants in 13 countries on six continents. However, there was little or no communication among them. This led to considerable duplication of efforts. For example, Black and Decker's eight design centers once produced as many as 260 different motor sizes.

The global corporation focuses on similarities across world markets and aggressively works to "sensibly force suitably standardized products and services on the entire globe." These global marketers realize substantial economies through standardization of production, distribution, marketing, and management. They 
translate their efficiency into greater value for consumers by offering high quality and more reliable products at lower prices. In the case of Black and Decker, a global restructuring of operations could reduce the number of motor sizes from 260 to just 10 , resulting in substantial cost savings.

Levitt would advise an auto company to make a world car, a shampoo company to make a world shampoo, and a construction company to make a world tractor. In fact, some companies have successfully marketed global products. Coca-Cola, McDonald's hamburgers, and Marlboro cigarettes are well-known examples.

Note, however, the idea of a fully standardized global product is a near-myth that has caused great confusion. Such products are very rare and hard to attain. Ford's experiences illustrate the point. ${ }^{8}$

Ford used to develop and market passenger cars tailored separately to North America and Europe. However, Ford began to move towards the design of a "world car" in the mid-size range, which could be marketed worldwide. The Ford Escort, for example, was originally planned as a "world car," pooling design, engineering, and manufacturing capabilities on both sides of the Atlantic. However, design engineers in Europe and North America were unable to agree, resulting in two distinctly different models sharing only one common part - a waterpump seal. Learning lessons from the failure, Ford was able to develop Mondeo, launched in 1993 in Europe and in the United States in 1994. However, it was an extremely complex and costly development project taking over 8 years, involving 800 engineers in three engineering centers in the United States, U.K., and Germany, and costing \$6 billion which was twice the amount spent on the Taurus in 1993.

Even in the above cases, some adaptation took place. The Mondeo has U.S. adaptation called the Ford Contour and the Mercury Mystique. In Europe, the Mondeo is the second most expensive Ford, providing a $\$ 2,000-\$ 3,000$ per unit profit. In the United States, however, due to fierce price competition, Contour and Mystique are unlikely to break even. Taking another examples, Coca-Cola is less sweet or less carbonated in certain countries, McDonald's uses chili sauce instead of ketchup on its hamburgers in Mexico.

Companies are certainly justified in looking for more standardization, regionally if not globally. Yet, companies must remember that while standardization might save some costs, competitors are always ready to offer products tailored to the needs of 
customers in each country. Further, resistance arises from country managers because regional standardization puts more power into the hands of the regional manager and less in the hands of each country manager. Corporate headquarter has to play a stronger role to counter the resistance.

When thinking of adaptation versus standardization, a company needs to think in terms of incremental revenue versus incremental cost. Consider the following example ${ }^{9}$ :

Nestle had difficult time in penetrating Malaysian market for chocolate bars with its imported KitKat chocolate wafer bar. The difficulties were two-fold: distributing rich, meltable chocolate in hot climates and a brusing price war. Since Malaysia was a leading exporter of cocoa beans, Nestle considered making chocolate bars there. However, the quality of the Malay beans was not rich enough and the Malaysian market was not big enough to justify its own chocolate bar plant. The solution: produce a slightly different Nestle's KitKat chocolate wafer bar for the entire Asian region from Malaysia, using local cocoa. Nestle's lab in Singapore devised a formula to raise the candy bar's melting point by reducing the fat content. The factory technicians redesigned their equipment to handle the tougher native beans. Although the new KitKat does not taste as rich as the imported kind, it certainly carries a tasty price, about $30 \%$ cheaper than the imports. Even at this price, the company can maintain margins of about $20 \%$. KitKat became one of the fastest-growing products in Malaysia in its category.

Rather than assuming that the company's domestic product can be introduced "as is" in another country, the company should review all possible adaptation elements such as product features, brand name, packaging, or prices and determine which adaptations would add more revenue than cost. Global standardization is not an all-or-nothing proposition but a matter of degree.

When the firm moves toward increased integration and coordination of not only marketing but also other activities at various stages in the value chain across country markets so as to realize potential synergy effects from global operations, it is called "transnational corporation."

One of the most successful "transnational corporations" is $\mathrm{ABB}$, formed by a merger between the Swedish company ASEA and the Swiss company Brown Boveri. ABB's products are industrial, including power transformers, electrical installations, 
instrumentation, auto components, air-conditioning equipment, railroad equipment, and so on. With annual revenues of $\$ 32$ billion and 210,000 employees, ABB is headed by Percy Barnevik, one of Europe's most dynamic CEOs. The company's motto is "ABB is a global company local everywhere." Barnevik established English as the company's official language and all financial operations must be reported in U.S-dollars. $A B B$ is organized with the aim of reconciling three contradictions: to be global and local; to be big and small; and to be radically decentralized with centralized reporting and control. ABB has only 170 staff people at headquarters (with about 19 nationalities among them), compared to the 3,000 who populate Siemens headquarters. The company's many product lines are organized into 8 business segments, 65 business areas, 1,300 companies, and 5,000 profit centers, with the average employee belonging to a profit center of around 50 employees. Each center has a country manager as well as a business sector manager who provides coordination for each business, such as transportation or electrical equipment, across national boundaries. Managers are regularly rotated among countries and mixed-nationality teams are encouraged. Depending on the type of business, some are treated as superlocal businesses with lots of autonomy and others as global businesses with major central control. Barnevik uses a proprietary software system called Abacus that allows manager to review performance data each month in each of the 5,000 profit centers. When the system indicates deficient performances, he contacts the appropriate country managers, business area managers, and local company presidents. He wants his managers to be locally knowledgeable but also attuned to global considerations in making their decisions. ${ }^{10}$

In sum, $\mathrm{ABB}$ and other "transnational corporations" exhibit the following organizational characteristics ${ }^{11}$ : first, they have organization structures which have no domestic-international split and put stronger emphasis on business dimension relative to geography and function. Second, they have management processes characterized by extensive horizontal coordination processes, global sharing of information and technology, and global strategic planning, budgets, performance review, and compensation. Third, their people tend to have multi-country careers and foreign nationals are found in third countries as well as bme countries. Finally, they have truly global culture that transcends the nationality of the home and foreign countries.

Today, I started my speech with an observation that over the next decade global firms would continue to face conflicting demands between localization and 
globalization. In this context, five important elements of global strategy will play important roles in global marketing: assessing core competence, configuring activities, selecting country-markets, choosing mode of entry, and coordinating activities.

In conclusion, there are two factors to keep in mind; First, the ideal strategy should match the level of globalization strategy to the industry's globalization potential. A business in an industry with low globalization potential should have a strategy that is not very global. Likewise, a business in an industry with high globalization potential should have a generally global strategy. Second, managers should avoid viewing strategies as global or not global on the basis of "all or nothing" logic. Flexibility matters. Global managers in the $21^{\text {st }}$ century should remember each dimension of strategy can have a different level of globalization.

\footnotetext{
${ }^{1}$ Discussions on core competence are largely based on Douglas, Susan P. and C. Samuel Craig (1995), Global Marketing Strategy, New York, NY: McGraw-Hill.

2 Discussions on activity location are largely based on Yip, George S. (1992), Total Global Strategy, Englewood Cliffs, NJ: Prentice Hall.

3 Magnet, Myron (1992), "Who's Winning the Information Revolution,” Fortune, November 30, pp. 74 78.

${ }^{4}$ Discussions on market selection are largely based on Yip, George S. (1992), Total Global Strategy, Englewood Cliffs, NJ: Prentice Hall.

5 Chang, Sea Jin (1998), Global Business Management, Seoul: Bak-Young Publishing Co.

${ }^{6}$ Discussion on standardization vs. adaptation are largely based on Kotler, Philip (1997), Marketing Management, Upper Saddle River, NJ: Prentice Hall.

${ }^{7}$ Levitt, Theodore (1983), "the Globalization of Markets," Harvard Business Review, May-June, pp. $92-$ 102.

8 Taylor, Alex (1993), “Ford s \$6 Billion Baby,” Fortune, June 28, pp. 76-81.

9 Rapoport, Carla (1994), “Nestle’ s Brand Building Machine,” Fortune, September 19, pp. 137-141.

10 See William Tayor, "The Logic of Global Business: An Interview with ABB' s Percy Barnevik," Harvard Business Review, March-April 1991, pp. 91-105; and Gail E. Schares, "Percy Barnevik's Global Crusade,” Business Week, Special Enterprise Issue, October 22, 1993, pp. 204-11.

11 Yip, George S. (1992), Total Global Strategy, Englewood Cliffs, NJ: Prentice Hall.
} 